Revista de Educação e Pesquisa em Contabilidade Journal of Education and Research in Accounting Revista de Educación e Investigatión en Contabilidad
REPeC, Brasília, v. 6, n. 1, art. 6, p. 90-111, jan./mar. 2012

Disponível online em www.repec.org.br

ISSN 1981-8610

\title{
A EVoluÇÃo da RSC No BRASIL ENTRE as EMPRESAS LISTADAS NA BoVESPa
}

\author{
Ana Gisbert \\ Ph.D. em Gestão e Contabilidade. \\ Professora de Contabilidade na Faculdade de Economia da Universidade Autônoma de Madri \\ Endereço: Campus Universitário de Cantoblanco, Rua Francisco Tomás y Valiente, n. 5 - 28049 - Madrid (Espanha) \\ E-mail: ana.gisbert@uam.es
}

\section{Vitória Lunardi}

Doutoranda em Contabilidade e Organização de Empresas na Faculdade de Economia da Universidade Autônoma de Madri. Professora de Contabilidade e Administração de Empresas na Faculdade Cenecista Nossa Senhora dos Anjos - Facensa. Endereço: Av. Dr. José Loureiro da Silva, 1991, Gravatai/RS.

E-mail:vitorialunardi@gmail.com

\section{Resumo}

O objetivo deste trabalho é analisar os avanços em responsabilidade social no Brasil, enfatizando o tipo de informação apresentada e o nível dos investimentos realizados durante o período 2003-2007. A análise empírica está baseada no conteúdo dos relatórios de RSC publicados pelas empresas com cotação na Bovespa, entre as quais estão as companhias que compõem a carteira do Índice de Sustentabilidade Empresarial e Responsabilidade Social Corporativa da bolsa de valores de São Paulo (Bovespa). A amostra analisada está composta por 48 companhias com cotação. Na análise empírica foi analisado o conteúdo dos relatórios anuais das empresas da amostra entre os anos de 2003 e 2007. Todos os projetos em RSC desenvolvidos pelas companhias da amostra foram classificados em 11 categorias, bem como em três grandes grupos de investimento: externo, interno e do meio ambiente. Os resultados deixam evidente a necessidade de potencializar a padronização do formato de apresentação dos relatórios de responsabilidade social corporativa devido à ausência de uniformidade. Observa-se também que as empresas investem em projetos que, na maioria dos casos, estão estritamente relacionados com a atividade principal que desenvolvem. Em relação ao crescimento do investimento, o maior avanço durante o período temporal analisado está no investimento externo, embora o investimento durante o período temporal tenha aumentado de forma considerável. O investimento do meio ambiente é que se manteve estável, devido especialmente a uma significativa redução no setor petrolífero.

Palavras-chave: Responsabilidade Social Corporativa; Relatórios Sócio-ambientais; Sustentabilidade.

Editado em Português, Inglês e Espanhol. Versão original em Espanhol.

Recebido em 09/09/10. Pedido de Revisão em 28/10/10. Resubmetido em 25/05/11. Aceito em 09/07/2011 por Valcemiro Nossa (Editor). Publicado em 27/03/12. Organização responsável pelo periódico: CFC/FBC/ABRACICON.

Copyright (C 2012 REPEC. Todos os direitos, até mesmo de tradução, são reservados. É permitido citar parte de artigos sem autorização prévia, desde que seja identificada a fonte. 


\section{INTRODUÇÃO}

Relatório de Responsabilidade Social Corporativa (RSC), relatório de sustentabilidade empresarial, balanço social corporativo ou relatório social são algumas das denominações utilizadas pelas empresas, pelo mundo profissional, pelo mundo acadêmico e pelos organismos reguladores para se referirem à informação publicada pela empresa focada em refletir sobre questões e projetos de caráter social e do meio ambiente.

Desde o começo da década de oitenta houve um crescente interesse entre as organizações empresariais do mundo inteiro pela informação sobre atividades de índole social e do meio ambiente. No Brasil, é a partir do fim daquela década que tal interesse cresce e se consolida, bem como o investimento dos empresários brasileiros em políticas de caráter social e de meio ambiente (ADAMS et al., 1998; SIQUIERA; VIDAL, 2002). Na atualidade, pode-se dizer que o Brasil é o país que lidera o desenvolvimento da filosofia sobre a RSC na América Latina, fundamentalmente através do apoio do conjunto empresarial brasileiro ao desenvolvimento dos indicadores do Instituto Ethos de Empresas de Responsabilidade Social e dos relatórios sociais do IBASE - Instituto Brasileiro de Análises Sociais e Econômicas, principais organizações em matéria de RSC na América Latina, que apresentam uma filosofia de trabalho similar à do GRI (Global Reporting Initiative).

A informação colhida nos relatórios de RSC permite difundir os diferentes projetos não só entre os investidores, como também entre outros agentes interessados no conjunto de atividades de natureza social e de meio ambiente da empresa: empregados e seus familiares, os sindicatos, os meios de comunicação, as organizações não-governamentais (ONGs), os sindicatos e o Estado; afinal de contas, os "Stakeholders". Na atualidade, pode-se observar uma tendência mundial em investir em empresas que podem ser classificadas como "socialmente responsáveis". No caso concreto do mercado da bolsa de valores do Brasil (Bovespa), existe desde dezembro de 2005 um índice específico (Índice de Sustentabilidade Empresarial - ISE), que reúne ações de 28 empresas com cotação na Bovespa, que são classificadas como "sustentáveis" de acordo com critérios sociais, de meio ambiente e econômico-financeiros ${ }^{1}$. Durante os primeiros 12 meses de atividade do índice, o número de companhias que se incorporaram à nova carteira passou de 28 para 34. Além disso, o crescimento do índice ao longo de 2006 foi de $37,82 \%$, contra $32,93 \%$ do Ibovespa ${ }^{2}$. O crescimento tanto do índice da bolsa de valores como do número de empresas de sua carteira é um evidente indicativo do interesse dos investidores por empresas socialmente responsáveis, bem como o interesse das próprias empresas em fazer parte de uma carteira de empresas direcionada a investidores interessados na sustentabilidade e na responsabilidade social.

No mundo acadêmico e profissional existe também um crescente interesse na pesquisa em RSC derivada principalmente do crescimento do investimento em empresas socialmente responsáveis, sustentáveis e, ao mesmo tempo, rentáveis. Por esse motivo, pode-se dizer que a pesquisa em RSC, e mais concretamente a análise do tipo de informação apresentada, bem como sua qualidade, uniformidade, clareza e confiabilidade, é determinante para fortalecer a confiança dos investidores e do restante de usuários na informação fornecida pelas empresas socialmente responsáveis.

A aposta da Bovespa no investimento nas empresas socialmente responsáveis e a evolução do índice ISE evidenciam o crescente interesse que o investimento socialmente responsável tem no Brasil. O objetivo principal deste trabalho é se aprofundar nos avanços que aconteceram em matéria de RSC entre as principais empresas do Brasil. Mais concretamente, estudar a evolução dos níveis de investimento, os tipos de projetos desenvolvidos ou o formato de apresentação da informação sobre RSC. Uma análise em profundidade da informação publicada em matéria de RSC é o primeiro ponto

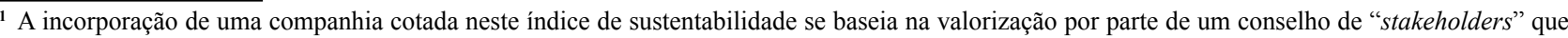
representam um conjunto da sociedade civil, de uma série de fatores baseados na relação da empresa com os empregados e fornecedores, a relação com a comunidade, com o governo corporativo da empresa e o impacto ambiental de suas atividades.

${ }^{2}$ Uma diferença de 14,84 pontos percentuais entre ambos os índices, no primeiro ano de existência do índice ISE.
} 
de partida para se poderem conhecer as razões que levam as empresas socialmente responsáveis a serem mais atraentes para os investidores nos mercados de capitais.

A amostra de análise está composta por um total de 48 empresas com cotação na bolsa de valores do Brasil (Bovespa), das quais 34 fazem parte do Índice de Sustentabilidade Empresarial (ISE), e as 14 restantes fazem parte do conjunto de empresas com cotação que investem em responsabilidade social, porém que ficam excluídas do índice. O período de análise abrange os anos entre $2003 \mathrm{e}$ 2007. Os dados da análise empírica foram obtidos diretamente dos relatórios de RSC publicados nas páginas web institucionais das empresas, bem como dos relatórios enviados à CVM - Comissão de Valores Mobiliários, organismo regulador dos mercados de bolsa de valores no Brasil. Os resultados da análise empírica permitem evidenciar uma tendência crescente nos níveis de investimento em projetos de RSC e permitem identificar as diferentes áreas de investimento, os setores mais atraentes, bem como identificar algumas das principais razões que levam uma empresa a ser socialmente responsável e transparente.

Este trabalho está estruturado da seguinte forma: a seção 2 analisa o crescente interesse pela RSC nas últimas décadas, bem como as principais linhas de pesquisa nesta matéria. La seção 3 aborda a análise da descrição da amostra e a metodologia de análise utilizada. Finalmente, as seções 4 e 5 analisam os resultados e colhem as principais conclusões do trabalho.

\section{OS AVANÇOS EM RESPONSABILIDADE SOCIAL CORPORATIVA}

\subsection{O crescente interesse pela RSC no âmbito governamental, social e empresarial}

A contabilidade como ciência social continuou desenvolvendo ao longo dos anos novos conceitos, novas tendências e novas práticas contábeis, adaptando-se à evolução e às novas demandas da sociedade. Conforme destaca Tinoco (2001, p. 14) "a existência das organizações empresariais não pode ser justificada exclusivamente pela sua capacidade de gerar benefícios aos seus proprietários". Neste sentido, na grande maioria das economias desenvolvidas surge a ideia de que a empresa não só deve elaborar relatórios de caráter financeiro, como também assumir compromissos de natureza econômica e social (MOREIRA, 2001).

Nos Estados Unidos, a ideia da responsabilidade social surge nos anos trinta (CARNEIRO, 1994; BATISTA, 2000). A guerra do Vietnã (1964-1973), o uso de armamentos sofisticados e danosos para o meio ambiente, bem como a discriminação de raça e sexo no trabalho, fizeram com que a sociedade norte-americana repensasse o posicionamento social das empresas, limitando as organizações a produzirem e venderem o que desejassem (TINOCO, 2001). Pode-se dizer que o desenvolvimento da RSC nos Estados Unidos surge graças à iniciativa da própria sociedade, embora também tenham acontecido numerosos avanços legislativos na matéria ${ }^{3}$. Os empresários, conscientes da demanda social, começaram a responder as exigências sociais para evitarem uma redução em suas cotas de mercado. Como indica Tinoco (2001, p. 126), entre o final dos anos 60 e o começo dos anos 70, a maioria das empresas norte-americanas começaram a preparar relatórios nos quais a informação econômica ficava vinculada a outra de caráter social e de meio ambiente: níveis de poluição, participação em obras culturais, contribuição da empresa para os meios de transporte coletivos da cidade e para outros benefícios para a comunidade, focando-se no papel do homem na empresa e desta na sociedade.

As empresas norte-americanas foram pioneiras na publicação de informação social, apesar de não existir uma legislação que as obrigasse a publicar anualmente este tipo de relatórios. Talvez por isso e pelas características do liberalismo econômico dos Estados Unidos, a nomenclatura utilizada para estes relatórios fosse bastante variável: social audit, social balance sheet, social accountability, social responsibility report, social report. O Dow Jones Sustainability Index (DJSI) definiu em 1999 a sustentabilidade de acordo com critérios econômicos, sociais e do meio ambiente, formalizando a

\footnotetext{
${ }_{3}^{3}$ A ideia da RSC foi introduzida nos Estados Unidos por alguns líderes empresariais, como Rockefeller, Carnegie, Ford ou Hewlett - Packard. No entanto, o avanço não aconteceu até os anos sessenta, quando, junto à pressão social, foi realizada uma série de avanços legislativos.
} 
divulgação desta informação no Social Audit, um relatório econômico-social focado nos consumidores, nos clientes e na sociedade em geral.

No âmbito da União Europeia, aconteceram numerosos avanços a favor do desenvolvimento da RSC. Os primeiros estímulos começaram no ano 2000, quando o Conselho Europeu de março daquele mesmo ano evidenciou a necessidade de se garantir um crescimento econômico sustentável para que fosse alcançado o objetivo estratégico de ser a economia mais competitiva e dinâmica do mundo ${ }^{4}$. Desde então, a União Europeia desenvolveu diversas iniciativas nas quais evidencia o seu compromisso com o desenvolvimento sustentável e com a RSC. Os avanços mais destacados desenvolvidos pela EU em matéria de RSC estão expostos na Tabela a seguir:

Tabela 1: Iniciativas da União Europeia a favor do desenvolvimento sustentável e a RSC

\begin{tabular}{|c|c|}
\hline Ano & Documento e principal objetivo \\
\hline 2001 & $\begin{array}{l}\mathrm{COM}^{5} \text { (2001) 366: Publicação do "Livro verde" para estimular o desenvolvimento de um marco europeu para a responsa- } \\
\text { bilidade social das empresas. }\end{array}$ \\
\hline 2002 & $\begin{array}{l}\text { COM (2002) 347: "A responsabilidade social das empresas: uma contribuição empresarial para o desenvol- } \\
\text { vimento sustentável". Objetivo: proposta de estratégia de promoção da RSE e Criação do Fórum Multilateral } \\
\text { Europeu sobre RSE. }\end{array}$ \\
\hline 2004 & $\begin{array}{l}\text { COM (2004): "Green Paper Promoting a European Framework for Corporate Social Responsibility". Objetivo: a } \\
\text { promoção da inovação, da transparência e da convergência das práticas e instrumentos de Responsabilidade Social. }\end{array}$ \\
\hline 2005 & $\begin{array}{l}\text { COM (2005): Reconhece que a responsabilidade social das empresas pode desempenhar uma função-chave na hora de } \\
\text { contribuir para o desenvolvimento sustentável e reforçar, ao mesmo tempo, o potencial inovador e a competitividade da } \\
\text { Europa. Objetivo: Continua sendo debatida a maneira de promover a RSE no marco do Acordo de Cotonú e a Nova Estra- } \\
\text { tégia para a África. } \\
\text { Decisão 2005/600/CE do Conselho: Relativa às Diretrizes para as políticas de emprego dos Estados-membros. } \\
\text { COM (2005) 33: A Comissão Europeia propõe uma nova Agenda Social que compreende o período entre } 2006 \text { e 2010. Objetivo: } \\
\text { chegar a ser "uma Europa social na economia mundial: empregos e novas oportunidades para todos". } \\
\text { COM (2005) 658: Estabelece uma estratégia no longo prazo que combina as políticas para o desenvolvimento sustentável } \\
\text { do meio ambiente, econômico e social. Objetivo: melhorar de forma sustentável o bem-estar e as condições de vida das } \\
\text { gerações presentes e futuras. }\end{array}$ \\
\hline 2006 & $\begin{array}{l}\text { COM (2006): "Colocar em prática a associação para o crescimento e o emprego: fazer da Europa um pólo de ex- } \\
\text { celência da responsabilidade social das empresas". Objetivo: estabelecer uma nova fase na evolução da política } \\
\text { europeia no que estiver relacionado à RSE. }\end{array}$ \\
\hline 2007 & $\begin{array}{l}\text { COM (2007) 642: "Relatório provisional sobre a Estratégia de Desenvolvimento Sustentável 2007”. Objetivo: con- } \\
\text { sidera que os avanços obtidos foram modestos, mas que o desenvolvimento político tanto em nível da UE como dos } \\
\text { Estados-membros progrediu especialmente em matéria de mudanças climáticas, energia limpa e saúde. }\end{array}$ \\
\hline 2009 & $\begin{array}{l}\text { Tratado de Lisboa: Dota a UE de instituições modernas e aperfeiçoa os seus métodos de trabalho para poder enfren- } \\
\text { tar os desafios do mundo contemporâneo, reforça a democracia na UE e melhora a sua capacidade de defender os } \\
\text { interesses dos seus cidadãos. Objetivo: resolver problemas como a globalização, a mudança climática, a evolução } \\
\text { demográfica, a segurança e a energia. } \\
\text { P6_TA (2009) 0190: Resolução do Parlamento Europeu sobre a responsabilidade social das empresas de terceiriza- } \\
\text { ção nas cadeias de produção ( } 2008 / 2249 \text { (INI)). }\end{array}$ \\
\hline
\end{tabular}

Fonte: Síntese da legislação da EU, em http://europa.eu/legislation_summaries e http://europa.eu/lisbon_treaty/index_es.htm

\footnotetext{
${ }^{4}$ Comissão Europeia: Dez anos da Estratégia Europeia de Emprego. Luxemburgo: Escritório de Publicações Oficiais das Comunidades Europeias. 2007 -43 pp. -17.6 x $25 \mathrm{~cm}$. ISBN 978-92-79-06583-5.

${ }^{5}$ Comunicação da Comissão das Comunidades Europeias.
} 
No Brasil, o debate sobre o Relatório de RSC teve início em 1976 com a mobilização dos dirigentes empresariais, liderada pela Associação dos Diretores Cristãos de Empresas (ADCE) (TINOCO, 2001). No entanto, o desenvolvimento da RSC no Brasil começou no final dos anos oitenta, e o debate se intensificou nos meados dos anos noventa. Neste momento, algumas empresas ${ }^{6}$ dão os primeiros passos na divulgação deste tipo de informação (ARAÚJO, 2003). Entretanto, a ideia somente ganhou força quando, em março de 1977, o sociólogo Herbert de Souza (1935-1977) escreveu o artigo "Empresa pública e cidadã", no qual é incentivada a publicação do relatório de RSC no Brasil, com o objetivo de que as empresas brasileiras prestassem contas das suas atividades sociais tanto dentro quanto fora da organização (NEGRA et al., 2002).

A partir deste momento, aconteceu uma série de iniciativas governamentais ${ }^{7}$. Por exemplo, na cidade de São Paulo foi aprovada a Resolução número 05/98, a qual institui o "Dia da Empresa Cidadã" e o "Carimbo Empresa Cidadã" com o intuito de se estimular e reconhecer o trabalho realizado pelas empresas que apresentam um relatório social de qualidade. Este tipo de certificado de qualidade também se instaurou posteriormente em outras cidades, como Porto Alegre (no Estado do Rio Grande do Sul). Além disso, em Porto Alegre a publicação do relatório social é obrigatória para as empresas com sede nesta cidade e com mais de 20 empregados (KROETZ, 2000).

Juntamente às iniciativas anteriores, em dezembro de 2004 foi publicada no Brasil a certificação NBR 16001 (gerenciada pela Associação Brasileira de Normas Técnicas, ABNT), a qual reúne um conjunto de requisitos associados à ética empresarial, à cidadania, aos direitos humanos e ao desenvolvimento sustentável. Esta certificação tem como objetivo criar uma série de diretrizes nacionais de conduta para que a empresa possa ser considerada socialmente responsável.

A publicação de um relatório sobre RSC é uma prática cada vez mais consolidada entre as empresas brasileiras, surgindo daí o interesse em analisar detalhadamente o seu conteúdo e a sua estrutura, particularmente das empresas que possuem cotação; dessa maneira, pode-se determinar o tipo de informação, a sua quantidade, a sua qualidade e, para concluir, a sua utilidade para os usuários deste tipo de informação.

\subsection{A revelação de informação sobre responsabilidade social corporativa}

A maior parte da pesquisa em RSC foi focada principalmente em se analisar os fatores determinantes da publicação de informação sobre RSC. De forma geral, foram observados vários motivos pelos quais as empresas começaram a se interessar em publicar relatórios de RSC. De acordo com a Lewis e Unerman (1999) ou Andrande et al. (2002), um dos principais motivos estão relacionados com a satisfação da demanda informativa dos stakeholders e com o favorecimento da imagem empresarial. Junto aos acionistas, os stakeholders demandam cada vez mais informação de caráter sócio-ambiental, exercendo pressão sobre as empresas, que percebem que cada vez mais é necessária a publicação de informação sobre os seus projetos sociais e do meio ambiente. Os relatórios de RSC são uma das melhores formas de exposição da ética de uma organização com informação quantitativa e qualitativa sobre os seus projetos sociais e do meio ambiente. $\mathrm{O}$ crescente interesse da empresa em apresentar estes relatórios pode ser justificado em sua utilidade para impulsionar mudanças na empresa (DIERKES; ANTAL, 1985). As mudanças costumam acontecer como resultado da pressão exercida pelos stakeholders externos ou internos, incluindo-se os próprios diretores, que, baseados na informação publicada no relatório, podem tomar diferentes posicionamentos no comando da empresa. Além disso, para os diretores o relatório de RSC serve como guia do planejamento da empresa em termos de objetivos e metas na área sócio-ambiental.

A informação colhida nos relatórios de RSC pode variar em função do setor, do tamanho da empresa, da estrutura e estilo de direção ou do contexto regional e temporal no qual a empresa está inserida (ADAMS et al., 1998; LEWIS; UNERMAN, 1999; TEOH; THONG, 1984). Estes fatores,

\footnotetext{
${ }^{6}$ A primeira empresa a publicar um relatório social foi a empresa estatal Nitrofértil, em 1984.

${ }^{7}$ Em nível nacional, foi desenvolvido no ano de 1999 um Projeto de Lei (32/99) sobre Responsabilidade Social Corporativa, mas que na atualidade ainda não foi definitivamente aprovado pelo Congresso Nacional (Reis e Medeiros, 2007)
} 
juntamente à pressão exercida pelos stakeholders, serão determinantes no interesse e na capacidade da empresa em produzir informação de caráter social e de meio ambiente.

Os relatórios publicados pelas empresas brasileiras diferem significativamente daqueles publicados pelas empresas européias e norte-americanas ${ }^{8}$ (FREIRE; REBOUÇAS, 2001). Conforme poderá ser observado posteriormente, a maior parte das empresas brasileiras que possuem cotação publicam os seus relatórios de responsabilidade social se baseando no modelo do IBASE (Instituto Brasileiro de Análises Sociais e Econômicas) conjuntamente com os indicadores do Instituto Ethos de Responsabilidade Social. Este modelo consiste numa apresentação parcialmente adaptada dos indicadores GRI (Global Reporting Initiative), embora com uma ênfase maior em aspectos relacionados com o emprego, a educação, a melhoria da qualidade de vida das pessoas e que faz com que as empresas brasileiras utilizem com mais freqüência este modelo de indicadores devido às próprias características institucionais do Brasil.

Até a década de noventa podiam ser observadas várias tendências e movimentos na publicação de informação de caráter sócio-ambiental. Por exemplo, nos primeiros modelos do IBASE podia ser observada uma clara tendência focada na publicação de informação mais relacionada com as ações sociais da empresa, enquanto existia outra tendência que dava prioridade aos aspectos de gerenciamento e transparência, de forma similar às pesquisas de benchmarking do Instituto Ethos. Finalmente, um terceiro movimento estava focado em informação do meio ambiente, de forma similar aos relatórios de sustentabilidade do Conselho Empresarial Brasileiro para o Desenvolvimento Sustentável (CEBDS). Na atualidade, existe um grande interesse pela integração das informações sociais e do meio ambiente num único documento (LINE et. al., 2002).

Com relação à profundidade e tecnicidade do conteúdo e do formato dos relatórios, existe uma grande divergência de opiniões na literatura acadêmica e profissional. Alguns autores defendem a apresentação de relatórios mais simplificados, argumentando que o seu principal objetivo é a divulgação de informação para um público (stakeholders) que, em linhas gerais, está pouco ou nada familiarizado com os aspectos técnicos da informação financeira. No entanto, outra linha defende a necessidade de os relatórios possuírem o rigor técnico necessário e que, mesmo assim, possam ser utilizados e interpretados por outros stakeholders, diferentes daqueles dos acionistas (SHAOUL, 1998; PRESTON, 1981). Outro debate está focado na necessidade de regular e, portanto, obrigar que a elaboração dos relatórios de RSC seja obrigatória. Os defensores de uma maior regulação dos relatórios alegam duas razões principais (ROBERTS, 1998; SUTTON; ARNOLD, 1998): (a) que os stakeholders possuem pouco poder de pressão para demandar certo tipo de informação e, muitas vezes, as suas demandas são ignoradas pelas empresas; e (b) o nível de qualidade dos relatórios divulgados não é satisfatório. Dessa maneira, em alguns países, como a França, já foram desenvolvidos mecanismos de regulação destes relatórios (FREIRE; REBOUÇAS, 2001). No entanto, no caso do Brasil, a publicação deste tipo de relatórios ainda não está regulamentada em nível nacional (SIQUEIRA; VIDAL, 2002). Não obstante, como já foi falado anteriormente, existem algumas iniciativas municipais ${ }^{9}$ de regulação do relatório de RSC. Para completar, a Agência Nacional de Energia Elétrica - ANEEL - elaborou uma resolução que torna obrigatória a publicação do relatório de RSC por empresas do setor elétrico desde 2003.

\section{SELEÇÃO DA AMOSTRA E COLETA DE DADOS}

O estudo empírico tem como objetivo realizar uma análise bastante profunda da informação sobre RSC publicada pelas empresas da amostra, assim como a evolução do investimento em RSC

\footnotetext{
${ }^{8} \mathrm{Na}$ Europa, a maior parte das empresas utiliza o modelo desenvolvido pela GRI (Global Reporting Initiative), focado em fatores de meio ambiente e de sustentabilidade. A heterogeneidade presente na forma de apresentação da informação sobre RSC promoveu o desenvolvimento em nível internacional de GRI (Global Reporting Initiative), uma instituição da qual participam empresas, organizações governamentais e sociais dos cinco continentes. O objetivo principal desta organização é difundir a importância da publicação de relatórios de RSC, bem como publicar uma serie de diretrizes que permitem homogeneizar a informação com o intuito de estar provida de utilidade para os diferentes stakeholders. Como na Europa, nos Estados Unidos o modelo mais utilizado pelas empresas que possuem cotação é o GRI.

9 Os municípios de São Paulo (SP) e Porto Alegre (RS) já regulamentaram o relatório RSC.
} 
durante o período compreendido entre 2003 e 2007. A amostra de análise está composta por um total de 48 empresas de vinte e um setores da economia que fazem parte tanto da carteira do Índice de Sustentabilidade Empresarial (ISE) quanto das empresas da Bovespa com maior responsabilidade social ${ }^{10}$ dentro do marco do projeto desenvolvido pela Bovespa "em boa companhia". O anexo 1 demonstra o conjunto de empresas que fazem parte da amostra.

34 do total de 48 empresas da amostra fazem parte do Índice de Sustentabilidade Empresarial (ISE $)^{11}$ da Bovespa. As 14 empresas restantes foram selecionadas através da página web da Bovespa dedicada ao projeto "Em Boa Companhia", que tem como objetivo a divulgação das boas práticas corporativas empresariais ${ }^{12}$.

A informação utilizada na análise empírica procede dos relatórios de RSC das empresas da amostra, assim como de outro tipo de informação publicada pelas empresas nos seus relatórios anuais ou em outros documentos à disposição do público. Concretamente, obteve-se informação através das páginas web das empresas da amostra, por contato via e-mail, bem como dos relatórios da Bolsa de Valores Brasileira (Bovespa). A informação analisada compreende o período entre 2003 e 2007.

Uma vez coletados todos os relatórios de RSC, bem como a informação adicional disponível de todas as empresas da amostra, foi realizada a análise aprofundada do seu conteúdo. Mais concretamente: (1) foram identificados todos os projetos desenvolvidos pelas empresas às quais se fazia referência em seus relatórios, bem como em outras fontes de informação utilizadas; (2) os projetos foram agrupados num total de 11 categorias com o objetivo de se poder realizar uma análise comparativa dos tipos de projetos desenvolvidos por cada setor industrial; (3) foi analisada a evolução dos níveis de investimento em projetos sociais e de meio ambiente ao longo do período de estudo (entre 2003 e 2007) com o objetivo de observar se existe um crescente interesse e compromisso das empresas em investir em projetos desta natureza. Nesta última análise, o investimento em RSC foi agrupado em três indicadores: (1) indicador social interno (ISI), associado ao investimento da empresas nos seus próprios empregados (contribuições sociais obrigatórias, aposentadorias, planos de saúde, segurança e saúde no trabalho, educação, cultura, formação e desenvolvimento profissional, creches para os filhos, participação nos lucros, vale-transporte, atividades recreativas, moradia); (2) indicador social externo (ISE), relacionado com o investimento na sociedade; e (3) indicador de meio ambiente (IMA), relacionado com o investimento da empresa em projetos de meio ambiente.

\section{ANÁLISE DOS RESULTADOS}

\subsection{O formato de apresentação dos relatórios de RSC}

Conforme se destacou anteriormente, uma das consequências da falta de regulamentação da apresentação de informação sobre RSC é a ausência de um modelo único de apresentação. Os dados colhidos na tabela 2 deixam a evidência de que, durante o período compreendido entre 2003 e 2005, a maior parte das empresas brasileiras apresentou tendência em apresentar o relatório RSC de acordo com modelos próprios ou com o modelo IBASE (Instituto Brasileiro de Análises So-

\footnotetext{
${ }_{10}$ O projeto "em boa companhia" de BOVESPA tem como objetivo a divulgação das boas práticas corporativas empresariais, mais concretamente dos projetos de responsabilidade social e de meio ambiente desenvolvido por um conjunto de empresas que possuem cotação, demonstrando, assim, o poder do investimento socialmente responsável no desenvolvimento econômico sustentável do país.

${ }^{11}$ Este Índice, referência essencial para realizar investimentos socialmente responsáveis, tem como objetivo evidenciar a rentabilidade de uma carteira composta por ações de empresas com reconhecido compromisso com a responsabilidade social e atuar como mecanismo de controle das boas práticas no ambiente empresarial brasileiro. A incorporação de uma empresa a este índice depende de um conselho deliberativo presidido pela Bolsa de Valores Brasileira - Bovespa, que é o órgão responsável pelo desenvolvimento do índice ISE, pelo seu cálculo e pela sua gestão técnica. Junto à Bovespa, organizações como a ABRAPP (Associação Brasileira das Entidades Fechadas de Previdência), ANBID (Associação Nacional dos Bancos de Investimento), APIMEC (Associação dos Analistas e Profissionais de Investimento do Mercado de Capitais), IBGC (Instituto Brasileiro de Governança Corporativa), IFC (Corporação Financeira Internacional), Instituto Ethos de Empresas e Responsabilidade Social e o Ministério do Meio Ambiente, fazem parte do Conselho.

${ }^{12}$ A página de acesso direto a este projeto da Bovespa é a seguinte: http://www.bovespa.com.br/wrs/Index.asp
} 
ciais e Econômicas), no qual são utilizados os indicadores do Instituto Ethos de Responsabilidade Social. No entanto, esta tendência parece ter sofrido modificação nos últimos anos em favor do modelo GRI ou a combinação deste com os indicadores do Instituto Ethos de Responsabilidade Social. Se no ano de 2003, somente 3 empresas das 48 analisadas na amostra seguiam o modelo GRI ou uma combinação GRI/Ethos, em 2007 este número aumentou para 30, ou seja, para 62,5\% da amostra. Os resultados deixam evidente a tendência das empresas brasileiras em migrar para formatos de elaboração de relatórios RSC com uma maior repercussão e reconhecimento internacional e, afinal de contas, para uma aposta pela melhoria da qualidade da informação em matéria de RSC.

Em relação à forma de publicação do relatório RSC, mais de 50\% das empresas analisadas ( $54,58 \%$ de média no período) publicam o relatório RSC de forma independente, diante dos $45,42 \%$ restantes, que integram a informação sobre RSC nos relatórios anuais. Não foram observadas modificações significativas nesta proporção no transcurso do período analisado.

Tabela 2: Distribuição da amostra de empresas em função do modelo de relatório de RSC aplicado. Análise para o período entre 2003 e 2007.

\begin{tabular}{c|c|c|c|c|c}
\hline \multirow{2}{*}{ Ano } & & GRI/ Ethos (Ibase) & GRI & Ethos (Ibase) & Próprios \\
\hline \multirow{2}{*}{2003} & Número de empresas & 2 & 1 & 22 & 23 \\
\cline { 2 - 5 } & $(\%)$ & 4,17 & 2,08 & 45,83 & 47,92 \\
\hline \multirow{2}{*}{2004} & Número de empresas & 2 & 2 & 23 & 21 \\
\cline { 2 - 5 } & $(\%)$ & 4,17 & 4,17 & 47,92 & 43,75 \\
\hline \multirow{2}{*}{2005} & Número de empresas & 4 & 3 & 24 & 17 \\
\cline { 2 - 6 } & $(\%)$ & 8,33 & 6,25 & 50,00 & 35,42 \\
\hline \multirow{2}{*}{2006} & Número de empresas & 13 & 6 & 19 & 10 \\
\cline { 2 - 6 } & $(\%)$ & 27,08 & 12,50 & 39,58 & 20,83 \\
\hline \multirow{2}{*}{2007} & Número de empresas & 23 & 7 & 13 & 5 \\
\cline { 2 - 6 } & $(\%)$ & 47,92 & 14,58 & 27,08 & 10,42 \\
\hline \multirow{2}{*}{ Total } & Número de observações & 44 & 19 & 101 & 76 \\
\cline { 2 - 6 } & $(\%)$ & $18,33 \%$ & $7,92 \%$ & $42,08 \%$ & $31,67 \%$ \\
\hline
\end{tabular}

Juntamente à diversidade existente nos formatos de apresentação, a extensão dos relatórios também é muito variável. A tabela 3 reúne a informação sobre a extensão média dos relatórios de RSC por setores industriais. $\mathrm{O}$ Painel $\mathrm{A}$ faz referência à extensão de cada relatório, medida pelo número de páginas, enquanto que o Painel $\mathrm{B}$ faz referência à extensão de cada relatório medida em função do número de epígrafes coletados.

Concentrando-nos no número de páginas, pode ser observada uma clara tendência de crescimento na extensão dos relatórios RSC para o período analisado. Esta mesma tendência também é observada no Painel $\mathrm{B}$ ao se analisar o número de epígrafes dos relatórios. No entanto, a tendência de crescimento no número de epígrafes não é generalizável a todos os setores industriais. Afinal de contas, os resultados indicam um aumento da extensão e dos conteúdos nos relatórios RSC.

Os relatórios de maior extensão correspondem ao setor de energia elétrica, com uma extensão média de 687,8 páginas e com aproximadamente 100 epígrafes. Em segundo lugar estão as companhias do setor financeiro, com uma extensão média de 587 páginas e uma média de 77 epígrafes nos seus relatórios. Em terceiro lugar, o setor de siderurgia e metalurgia, com uma extensão média de 377,40 páginas e com aproximadamente 46 epígrafes nos seus relatórios. Nestes três setores assinalados existe uma tendência crescente na extensão de seus relatórios RSC, tanto no número de páginas quanto no número de epígrafes. 
Em contraposição a estes relatórios de grande extensão, outros setores coletam muito pouca informação sobre RSC. Os seus relatórios apresentam a informação de forma resumida, o que reflete o pouco investimento em RSC, focada fundamentalmente em aspectos internos da companhia.

Tabela 3: Extensão média dos relatórios RSC por setores industriais. Análise para o período entre 2003 e 2007.

Painel A: Análise do número de páginas

\begin{tabular}{l|c|c|c|c|c|c|c}
\hline \multicolumn{1}{c|}{ Setores industriais } & $\begin{array}{c}\text { Número de } \\
\text { empresas }\end{array}$ & $\mathbf{2 0 0 3}$ & $\mathbf{2 0 0 4}$ & $\mathbf{2 0 0 5}$ & $\mathbf{2 0 0 6}$ & $\mathbf{2 0 0 7}$ & $\begin{array}{c}\text { Média do } \\
\text { número de páginas }\end{array}$ \\
\hline Exploração mineral & 1 & 100 & 173 & 164 & 141 & 192 & 154,00 \\
\hline Financeiro & 5 & 403 & 600 & 532 & 468 & 932 & 587,00 \\
\hline Água e saneamento & 2 & 39 & 34 & 86 & 86 & 277 & 104,40 \\
\hline Holding Diversificado & 1 & 122 & 89 & 108 & 119 & 140 & 115,60 \\
\hline Energia elétrica & 10 & 367 & 287 & 834 & 809 & 1142 & 687,80 \\
\hline Papel e Celulose & 4 & 65 & 159 & 195 & 249 & 401 & 213,80 \\
\hline Exploração de rodovias & 3 & 117 & 91 & 197 & 259 & 288 & 190,40 \\
\hline Transporte aéreo e ferroviário & 3 & 148 & 211 & 278 & 235 & 293 & 233,00 \\
\hline Seguros & 1 & - & 61 & 90 & 63 & 93 & 76,75 \\
\hline Material de transporte & 2 & 78 & 24 & 30 & 37 & 126 & 59,00 \\
\hline Alimentação & 2 & 117 & 147 & 166 & 176 & 174 & 156,00 \\
\hline Petróleo, gás e biodiesel & 1 & 37 & 108 & 79 & 160 & 124 & 101,60 \\
\hline Petroquímico & 2 & 92 & 64 & 114 & 56 & 192 & 103,60 \\
\hline Produtos de uso pessoal & 1 & 108 & 67 & 155 & 132 & 107 & 113,80 \\
\hline Siderurgia e metalurgia & 4 & 202 & 212 & 274 & 616 & 583 & 377,40 \\
\hline Motores e equipamentos industriais & 1 & 14 & 21 & 13 & 32 & 32 & 22,40 \\
\hline Serviços diversos & 1 & - & - & - & 90 & 77 & 83,50 \\
\hline Aluguel de carros & 1 & - & - & 56 & 8 & 6 & 23,33 \\
\hline Tabacos & 1 & - & - & 69 & 77 & 80 & 75,33 \\
\hline Médico & 1 & - & - & 51 & 32 & 37 & 40,00 \\
\hline Embalagem & 1 & 33 & 29 & 33 & 40 & 2 & 27,40 \\
\hline Total & 48 & 2.042 & 2.377 & 3.524 & 3.885 & 5.298 & \\
\hline & & & & &
\end{tabular}

Painel B: Análise do número de epígrafes

\begin{tabular}{l|c|c|c|c|c|c|c}
\hline \multicolumn{1}{c|}{ Setores industriais } & $\begin{array}{c}\text { Número de } \\
\text { empresas }\end{array}$ & $\mathbf{2 0 0 3}$ & $\mathbf{2 0 0 4}$ & $\mathbf{2 0 0 5}$ & $\mathbf{2 0 0 6}$ & $\mathbf{2 0 0 7}$ & $\begin{array}{c}\text { Média do } \\
\text { número de páginas }\end{array}$ \\
\hline Exploração mineral & 1 & 17 & 23 & 26 & 35 & 17 & 23,60 \\
\hline Financeiro & 5 & 72 & 75 & 72 & 97 & 70 & 77,20 \\
\hline Água e saneamento & 2 & 9 & 8 & 12 & 13 & 27 & 13,80 \\
\hline Holding Diversificado & 1 & 11 & 13 & 7 & 8 & 16 & 11,00 \\
\hline Energia elétrica & 10 & 62 & 53 & 133 & 119 & 133 & 100,00 \\
\hline Papel e Celulose & 4 & 13 & 22 & 14 & 29 & 39 & 23,40 \\
\hline Exploração de rodovias & 3 & 17 & 18 & 29 & 26 & 20 & 22,00 \\
\hline Transporte aéreo e ferroviário & 3 & 12 & 45 & 30 & 25 & 32 & 28,80 \\
\hline Seguros & 1 & - & 19 & 9 & 8 & 6 & 10,50 \\
\hline
\end{tabular}




\begin{tabular}{l|c|c|c|c|c|c|c}
\hline Material de transporte & 2 & 29 & 9 & 10 & 10 & 23 & 16,20 \\
\hline Alimentação & 2 & 25 & 29 & 28 & 25 & 25 & 26,40 \\
\hline Petróleo, gás e biodiesel & 1 & 7 & 7 & 6 & 6 & 7 & 6,60 \\
\hline Petroquímico & 2 & 11 & 12 & 8 & 4 & 17 & 10,40 \\
\hline Produtos de uso pessoal & 1 & 11 & 13 & 19 & 14 & 13 & 14,00 \\
\hline Siderurgia e metalurgia & 4 & 42 & 40 & 37 & 60 & 55 & 46,80 \\
\hline Motores e equipamentos industriais & 1 & 9 & 10 & 7 & 5 & 5 & 7,20 \\
\hline Serviços diversos & 1 & - & - & - & 21 & 12 & 16,50 \\
\hline Aluguel de carros & 1 & - & - & 5 & 16 & 14 & 11,67 \\
\hline Tabacos & 1 & - & - & 11 & 19 & 7 & 12,33 \\
\hline Médico & 1 & - & - & 8 & 11 & 10 & 9,67 \\
\hline Embalagem & 1 & 18 & 18 & 18 & 18 & 13 & 17,00 \\
\hline Total & 48 & 365 & 414 & 489 & 569 & 561 & 479,6 \\
\hline
\end{tabular}

\subsection{Análise dos projetos de RSC desenvolvidos pelas empresas da amostra}

Uma vez analisadas as características da estrutura dos relatórios de RSC, foram analisados detalhadamente os projetos coletados em cada relatório RSC publicado pelas empresas da amostra no período entre 2003 e 2007 . Todos os projetos identificados foram classificados em 11 categorias, que permitem obter uma visão global dos tipos de projetos desenvolvidos. As categorias de investimento identificadas estão expostas na tabela a seguir:

Tabela 4: Descrição de cada uma das categorias nas quais foram classificados os projetos de RSC identificados.

\begin{tabular}{|c|c|}
\hline Categoria & Descrição \\
\hline Meio ambiente (1) & $\begin{array}{l}\text { Projetos destinados a prevenir e combater a poluição ambiental relacionada com a atividade principal da } \\
\text { empresa. O investimento em infra-estrutura não poluidora, bem como projetos externos destinados à proteção } \\
\text { do meio ambiente. }\end{array}$ \\
\hline $\begin{array}{l}\text { Desenvolvimento } \\
\text { profissional (2) }\end{array}$ & $\begin{array}{l}\text { Projetos de desenvolvimento profissional dos empregados da empresa, bem como a oferta de bolsas de pós- } \\
\text { graduação. }\end{array}$ \\
\hline Cidadania (3) & $\begin{array}{l}\text { Esta categoria representa o investimento realizado em projetos de desenvolvimento social: educação, cultura, } \\
\text { saúde, saneamento, residência, esporte, lazer, creches, alimentação e outros aspectos relacionados com a } \\
\text { cidadania, excluindo o gasto social nos próprios empregados da companhia. }\end{array}$ \\
\hline Comunidade (4) & $\begin{array}{l}\text { Projetos de voluntariado e ação social desenvolvidos pela empresa na própria comunidade social na qual } \\
\text { está integrada, como resposta à própria inserção da empresa numa comunidade que lhe proporciona não só a } \\
\text { infra-estrutura, como também o capital social que permite o desenvolvimento das suas atividades. Entre os } \\
\text { projetos desenvolvidos neste âmbito se encontram os incentivos à leitura nas escolas públicas ou o desenvol- } \\
\text { vimento de produção artesanal como uma opção sustentável de trabalho para a comunidade. }\end{array}$ \\
\hline Cultura (5) & Promoção de espetáculos, financiamento de atividades culturais: música, teatro, artes, etc. \\
\hline Educação (6) & $\begin{array}{l}\text { Investimentos em formação de professores, programas de estágios, bolsas para formação ou para cobrir os } \\
\text { gastos em livros, bem como outros gastos em educação e formação de crianças, adolescentes e adultos que } \\
\text { residem em regiões pobres. Os projetos têm como objetivo servir como mecanismo de promoção da cultura, } \\
\text { envolvendo não só os alunos, como também o conjunto da comunidade, favorecendo, dessa maneira, a sua } \\
\text { interação e inserção na sociedade. }\end{array}$ \\
\hline Saúde (7) & $\begin{array}{l}\text { Investimento em planos de saúde, assistência médica, programas de medicina preventiva, programas de qua- } \\
\text { lidade de vida e outros gastos em saúde com os antigos e atuais empregados, bem como com a sua família. }\end{array}$ \\
\hline Esporte (8) & Patrocínio e apoio de atividades esportivas. \\
\hline Fornecedores (9) & $\begin{array}{l}\text { Projetos destinados a fortalecer a relação com os fornecedores, estimulando o cumprimento dos contratos } \\
\text { estabelecidos, o aprimoramento das suas relações de associação e transmitindo os valores de seu código de } \\
\text { conduta a todos os participantes da sua cadeia de fornecimento. }\end{array}$ \\
\hline
\end{tabular}




\begin{tabular}{c|l}
\hline $\begin{array}{c}\text { Consumidores e } \\
\text { clientes (10) }\end{array}$ & $\begin{array}{l}\text { Projetos focados no desenvolvimento de produtos e serviços de confiança, capazes de minimizar o risco de um } \\
\text { possível mal à saúde dos seus usuários. Da mesma forma, neste âmbito também podem ser encontrados projetos } \\
\text { destinados a garantir que a publicidade e as instruções dos produtos garantam um uso adequado, bem como ser- } \\
\text { viços de atendimento ao cliente que garantam os seus direitos antes, durante e depois da compra do produto. }\end{array}$ \\
\hline \multirow{2}{*}{$\begin{array}{l}\text { Investimentos na equipe profissional da empresa, além dos direitos consolidados na legislação trabalhista e } \\
\text { dos convênios coletivos. Os projetos com marco nesta categoria estão relacionados com o investimento na } \\
\text { melhoria das condições de trabalho e de renda. Os projetos têm como objetivo uma maior implicação dos em- } \\
\text { pregados na gestão da empresa, promovendo a sua participação nos benefícios da empresa como acionistas, } \\
\text { formalizando planos de pensões ou estimulando a sua participação nos agrupamentos sindicais. }\end{array}$} \\
\hline
\end{tabular}

Como pode ser observado na Tabela 5, foi identificado um total de 16.381 projetos nos quais 44,12\% ( 7.227 projetos) são desenvolvidos pela empresa Petrobrás. Se não levarmos em consideração os dados precedentes desta empresa, o número de projetos é reduzido para $9.154^{13}$. Junto à Petrobrás, outros setores, como o da siderurgia e metalurgia, o financeiro, o elétrico ou o de material de transporte, também desenvolvem um número significativo de projetos, embora muito aquém da mencionada corporação.

A tabela 5 mostra detalhadamente para cada setor industrial analisado o número de projetos identificados em cada uma das categorias de investimento sócio-ambiental identificadas. A maior parte dos projetos desenvolvidos pela empresa Petrobrás se concentram nas áreas de cultura (2.201 projetos), cidadania (1.983 projetos, comunidade ( 808 projetos), meio ambiente (621 projetos), desenvolvimento profissional (565 projetos) e educação (461 projetos). Se não levarmos em consideração os dados desta corporação, as áreas com o maior número de projetos são: cultura (2.327 projetos), comunidade (1.352 projetos), meio ambiente (1.290 projetos), cidadania (1.054 projetos), educação (902 projetos) e empregados (695 projetos). As áreas nas quais é realizado um menor investimento correspondem às categorias "clientes" e "fornecedores".

\footnotetext{
${ }^{13}$ Ao se eliminar da amostra la empresa Petrobrás, as áreas mais afetadas são as seguintes: cidadana, com uma redução de $65,3 \%$, desenvolvimento profissional, com uma redução de $50,4 \%$, fornecedores, com uma redução de $49,07 \%$, cultura, com uma redução de $48,6 \%$, educação, com uma redução de $33,8 \%$, meio ambiente, com uma redução de $32,5 \%$, e comunidade, com $37,41 \%$ de redução no número de projetos.
} 


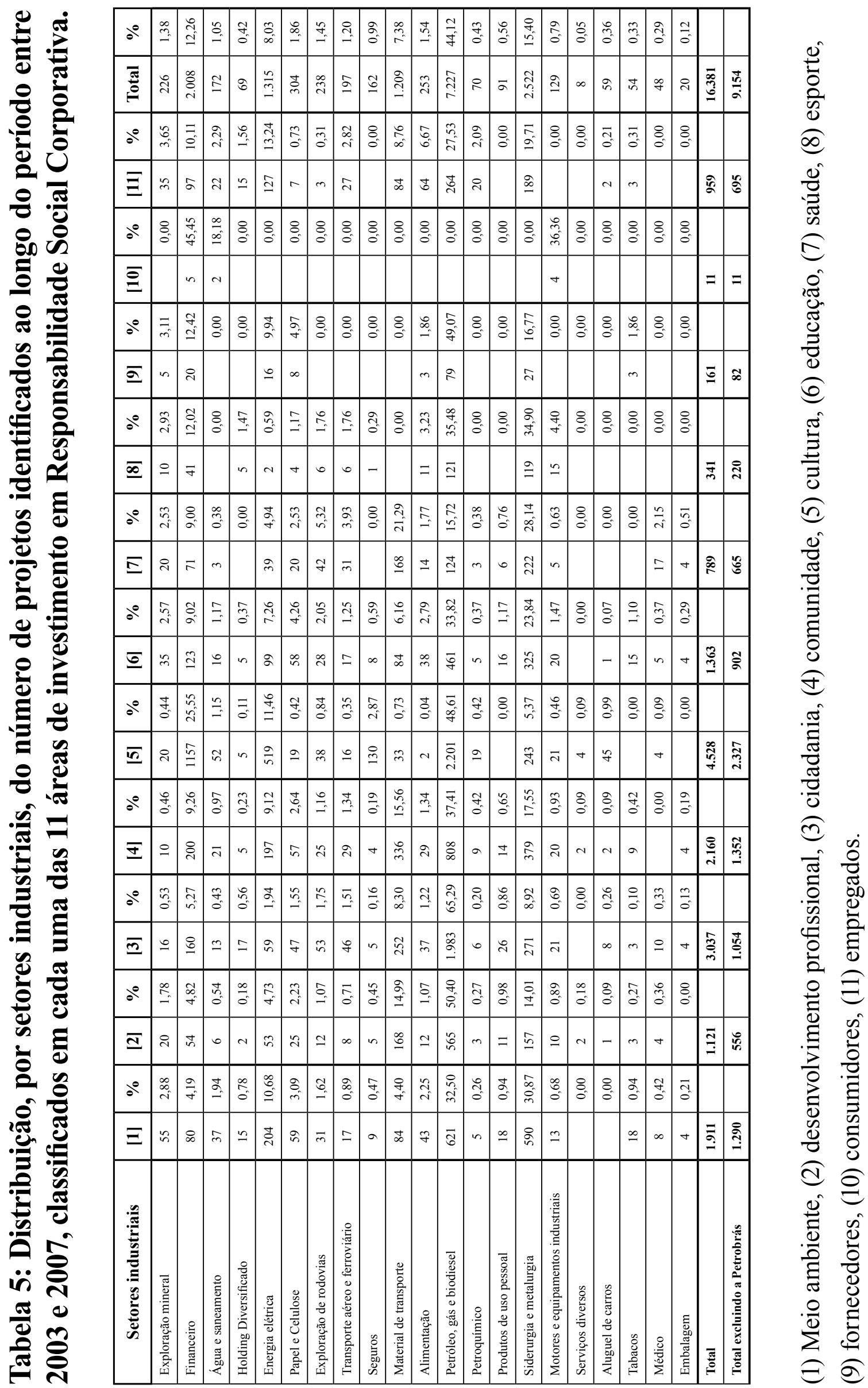


Se nos concentrarmos em cada uma das 11 categorias, pode-se destacar o seguinte:

Meio ambiente: a maior parte das empresas da amostra desenvolve projetos de meio ambiente. Somente dois setores são alheios a este tipo de investimento. No total foram identificados 1.911 projetos dos quais um total de 621 foram desenvolvidos pela Petrobrás, e 318 adicionais foram desenvolvidos por parte de empresas pertencentes a setores industriais cuja atividade possui um forte impacto ambiental. Como exemplo, o setor de energia elétrica desenvolve $10,68 \%$ dos projetos identificados (10 empresas e 204 projetos), seguido pelo setor de papel e celulose, com 4 empresas e 59 projetos (3,09\% do número total de projetos identificados), e pelo setor de exploração mineral, com 55 projetos desenvolvidos por uma só empresa (2,88\% do número total de projetos identificados);

Desenvolvimento Profissional: nesta categoria foi identificado um total de 1.121 projetos divididos em 20 dos 21 setores representados na amostra. 75\% das empresas analisadas (36 de 48) investem em projetos destinados ao desenvolvimento profissional dos seus empregados. Além disso, dos 1.121 projetos identificados, a maioria (565 no total, ou seja, 50,4\% do total) são desenvolvidos pela Petrobrás. O grande investimento em projetos de desenvolvimento profissional do setor de "petróleo, gás e biodiesel" está relacionado com o nível de complexidade das atividades desenvolvidas por este setor e com a necessidade de se investir na formação dos seus trabalhadores. Excluindo-se este setor, os projetos de desenvolvimento profissional em números significativos estão entre os setores de "material de transporte e "siderurgia e metalurgia".

Cidadania: um total de 47 empresas da amostras (98\%) investe em projetos sociais desta natureza. Mais uma vez, dos 3.037 projetos identificados, $65,3 \%$ destes (1.983 projetos) são desenvolvidos pela Petrobrás. Os 1.054 projetos restantes estão distribuídos entre empresas de outros dezenove setores industriais, entre os quais se destacam o de "siderurgia e metalurgia" e "material de transporte".

Comunidade: as 47 empresas que investem em projetos desta natureza representam $98 \%$ da amostra total. Mais uma vez, o setor de "petróleo, gás e biodiesel" é o mais envolvido neste tipo de projeto, com um total de 808 projetos (37,4\% dos projetos desta categoria). Junto a este setor, o de "siderurgia e metalurgia", "material de transporte", "setor elétrico" e o "setor financeiro" também se destacam em número de projetos.

Cultura: um total de 45 empresas da amostra (94\%) investe em 4.528 projetos culturais. O setor de "petróleo, gás e biodiesel" é o líder em investimento cultural, com 2.201 projetos (48,6\% de 4.528), seguido pelo setor "financeiro" e "energia elétrica", com 1.157 e 519 projetos respectivamente $(25,55 \%$ e $11,46 \%)$. As empresas menos envolvidas neste tipo de projeto pertencem ao setor de "alimentação", "médico", "serviços diversos" e "holding".

Educação: a área de investimento em educação conta com 1.363 projetos desenvolvidos na sua maioria pelas empresas do setor de "petróleo, gás e biodiesel”, com 461 projetos $(33,82 \%)$, seguido pelo setor "siderúrgico/metalúrgico", com 325 projetos $(23,84 \%)$.

Saúde: as empresas que investem neste tipo de projeto representam 33,33\% da amostra (16 empresas). No total, durante o período amostral são desenvolvidos 789 projetos dos quais 222 são executados pelo setor "siderúrgico/metalúrgico (28,14\% de 789$)$, seguido pelo setor de "material de transporte" (21,29\%), "petróleo" (15,72\%) e "financeiro" (9\%).

Empregados: nesta categoria foi identificado um total de 959 projetos divididos em 15 dos 21 setores representados na amostra. 87,5\% das empresas analisadas (42 de 48) investem na equipe profissional da empresa. Além disso, dos 959 projetos identificados, 264 (27,53\% do total) são desenvolvidos pela Petrobrás, seguido pelo setor "siderúrgico/metalúrgico", com 4 empresas e 189 projetos (19,71\% do total), e pelo setor de energia elétrica, com 10 empresas e 127 projetos (13,24\% do total). As empresas menos envolvidas neste tipo de projeto pertencem ao setor de "aluguel de carros", "tabaco" e "exploração de rodovias".

Categorias restantes (“esporte”, "fornecedores", “consumidores/clientes"): o número de projetos nestas três categorias restantes é significativamente inferior, especialmente para a categoria de 
"consumidores/clientes", na qual somente 8 empresas da amostra investem num total de 11 projetos. A categoria de "fornecedores" apresenta um interesse superior, com 161 projetos divididos entre 32 empresas, destacando-se mais uma vez a Petrobrás. No entanto, outros setores, como o "financeiro", "elétrico" ou o "siderúrgico/metalúrgico", também estão envolvidos no desenvolvimento de projetos dentro desta categoria. Finalmente, na área de "esporte" existe um total de 36 empresas da amostra (75\%) que investem em atividades esportivas, com um total de 341 projetos. Os setores "petróleo" e "siderúrgico/metalúrgico" são os que desenvolvem a maior parte dos projetos identificados, com um total de $121(35,5 \%)$ e $119(34,9 \%)$ projetos, respectivamente.

Tabela 6: Análise temporal do número de projetos identificados

Painel A: Análise temporal do número de projetos identificados para cada uma das 11 categorias identificadas.

\begin{tabular}{l|c|c|c|c|c|c|c|c|c|c|c|c}
\hline \multicolumn{1}{c|}{ Categoria de projetos } & $\mathbf{2 0 0 3}$ & $\mathbf{\%}$ & $\mathbf{2 0 0 4}$ & $\mathbf{\%}$ & $\mathbf{2 0 0 5}$ & $\mathbf{\%}$ & $\mathbf{2 0 0 6}$ & $\mathbf{\%}$ & $\mathbf{2 0 0 7}$ & $\mathbf{\%}$ & Total & $\mathbf{\%}$ \\
\hline 1 - Meio ambiente & 282 & 13,53 & 448 & 14,26 & 349 & 11,83 & 412 & 12,50 & 420 & 8,56 & 1.911 & 11,67 \\
\hline 2 - Desenvolvimento profissional & 131 & 6,29 & 201 & 6,40 & 207 & 7,01 & 229 & 6,95 & 353 & 7,19 & 1.121 & 6,84 \\
\hline 3 - Cidadania & 204 & 9,79 & 234 & 7,45 & 566 & 19,18 & 962 & 29,18 & 1.071 & 21,82 & 3.037 & 18,54 \\
\hline 4 - Comunidade & 287 & 13,77 & 436 & 13,88 & 553 & 18,74 & 360 & 10,92 & 524 & 10,68 & 2.160 & 13,19 \\
\hline 5 - Cultura & 671 & 32,20 & 1.175 & 37,41 & 557 & 18,87 & 478 & 14,50 & 1.647 & 33,56 & 4.528 & 27,64 \\
\hline 6 - Educação & 171 & 8,21 & 226 & 7,20 & 233 & 7,90 & 386 & 11,71 & 347 & 7,07 & 1.363 & 8,32 \\
\hline 7 - Saúde & 134 & 6,43 & 152 & 4,84 & 154 & 5,22 & 156 & 4,73 & 193 & 3,93 & 789 & 4,82 \\
\hline 8 - Esporte & 60 & 2,88 & 81 & 2,58 & 73 & 2,47 & 63 & 1,91 & 64 & 1,30 & 341 & 2,08 \\
\hline 9 - Fornecedores & 9 & 0,43 & 11 & 0,35 & 52 & 1,76 & 44 & 1,33 & 45 & 0,92 & 161 & 0,98 \\
\hline 10 - Consumidores e clientes & 2 & 0,10 & 2 & 0,06 & 1 & 0,03 & 3 & 0,09 & 3 & 0,06 & 11 & 0,07 \\
\hline 11 - Empregados & 133 & 6,38 & 175 & 5,57 & 206 & 6,98 & 204 & 6,19 & 241 & 4,91 & 959 & 5,85 \\
\hline Total & $\mathbf{2 . 0 8 4}$ & & $\mathbf{3 . 1 4 1}$ & & $\mathbf{2 . 9 5 1}$ & & $\mathbf{3 . 2 9 7}$ & & $\mathbf{4 . 9 0 8}$ & & $\mathbf{1 6 . 3 8 1}$ & \\
\hline
\end{tabular}

\section{Painel B: sem a Petrobrás}

\begin{tabular}{l|c|c|c|c|c|c|c|c|c|c|c|c}
\hline \multicolumn{1}{c|}{ Categoria de projetos } & $\mathbf{2 0 0 3}$ & $\mathbf{\%}$ & $\mathbf{2 0 0 4}$ & $\mathbf{\%}$ & $\mathbf{2 0 0 5}$ & $\mathbf{\%}$ & $\mathbf{2 0 0 6}$ & $\mathbf{\%}$ & $\mathbf{2 0 0 7}$ & $\mathbf{\%}$ & Total & $\mathbf{\%}$ \\
\hline 1 - Meio ambiente & 198 & 13,62 & 243 & 14,81 & 275 & 14,50 & 266 & 14,43 & 308 & 13,28 & 1.290 & 14,09 \\
\hline 2 - Desenvolvimento profissional & 85 & 5,85 & 92 & 5,61 & 105 & 5,54 & 127 & 6,89 & 147 & 6,34 & 556 & 6,07 \\
\hline 3 - Cidadania & 189 & 13,00 & 198 & 12,07 & 205 & 10,81 & 220 & 11,93 & 242 & 10,44 & 1.054 & 11,51 \\
\hline 4- Comunidade & 203 & 13,96 & 236 & 14,38 & 261 & 13,77 & 271 & 14,70 & 381 & 16,43 & 1.352 & 14,77 \\
\hline 5- Cultura & 340 & 23,38 & 387 & 23,58 & 527 & 27,80 & 446 & 24,19 & 627 & 27,04 & 2.327 & 25,42 \\
\hline 6 - Educação & 156 & 10,73 & 187 & 11,40 & 190 & 10,02 & 174 & 9,44 & 195 & 8,41 & 902 & 9,85 \\
\hline 7- Saúde & 118 & 8,12 & 122 & 7,43 & 128 & 6,75 & 130 & 7,05 & 167 & 7,20 & 665 & 7,26 \\
\hline 8 - Esporte & 44 & 3,03 & 43 & 2,62 & 41 & 2,16 & 44 & 2,39 & 48 & 2,07 & 220 & 2,40 \\
\hline 9 - Fornecedores & 9 & 0,62 & 11 & 0,67 & 19 & 1,00 & 21 & 1,14 & 22 & 0,95 & 82 & 0,90 \\
\hline 10 - Consumidores e clientes & 2 & 0,14 & 2 & 0,12 & 1 & 0,05 & 3 & 0,16 & 3 & 0,13 & 11 & 0,12 \\
\hline 11 - Empregados & 110 & 7,57 & 120 & 7,31 & 144 & 7,59 & 142 & 7,70 & 179 & 7,72 & 695 & 7,59 \\
\hline Total & $\mathbf{1 . 4 5 4}$ & & $\mathbf{1 . 6 4 1}$ & & $\mathbf{1 . 8 9 6}$ & & $\mathbf{1 . 8 4 4}$ & & $\mathbf{2 . 3 1 9}$ & & $\mathbf{9 . 1 5 4}$ & \\
\hline
\end{tabular}

A tabela 6 realiza uma análise temporal do número de projetos identificados em cada categoria de investimento sócio-ambiental identificado. Os painéis A e B permitem observar a evolução temporal do número de projetos identificados em cada categoria de investimento, bem como observar em cada ano qual categoria realizou um maior número de projetos. Diferentemente do Painel A, no Painel B se exclui a informação sobre a Petrobrás que, como já foi citado, é a empresa da amostra que desenvolve $44,12 \%$ dos projetos. 
De forma consistente com os dados da Tabela 6, o maior número de projetos se concentra na área de "cultura", na qual são desenvolvidos mais de $25 \%$ dos projetos analisados. Seguidas desta área aparecem "comunidade", "cidadania" e "meio ambiente".

Se nos concentrarmos na evolução temporal do número de projetos identificados em cada área, podemos observar que o maior crescimento aconteceu na categoria de "fornecedores", que passou de 9 para 45 projetos no período entre 2003 e 2007 (um crescimento médio de 95,46\%). Embora não seja a categoria mais importante, ela é a que apresenta um crescimento maior, seguido das categorias de "cultura" (63,22\% de crescimento médio), "cidadania" $(59,47 \%)$, "clientes" (37,50\%) e desenvolvimento profissional (30,3\%).

No Painel B são excluídos os projetos realizados pela empresa Petrobrás, observando-se, neste caso, mudanças substancialmente significativas nos crescimentos médios observados em cada uma das categorias de investimento analisadas. $\mathrm{O}$ crescimento passa a ser mais constante no tempo. $\mathrm{Na}$ Tabela B, a categoria de "clientes" possui o maior crescimento médio do período (37,5\%), seguida da categoria de "fornecedores" $(27,56 \%)$, "cultura" $(18,8 \%)$, "comunidade" $(17,82 \%$, "desenvolvimento profissional" (14,77\%), "empregados" (13,44\%) e "meio ambiente" (12,10\%).

Em linhas gerais, pode-se dizer que o investimento em RSC das empresas brasileiras está concentrado nas áreas de cultura, de cidadania, da comunidade, do meio ambiente e da educação, tanto de seus trabalhadores quanto do conjunto da sociedade, deixando evidente a importância da participação das empresas para o favorecimento do bem-estar coletivo. Além disso, a análise detalhada do conteúdo dos relatórios também sugere que as empresas utilizam a responsabilidade social como estratégia competitiva para fortalecer a sua imagem institucional através do marketing social. O nível e a natureza dos investimentos realizados dependem em grande parte do tipo de setor empresarial ao qual a empresa pertence e, para concluir, da sua atividade principal. Como exemplo, as empresas do setor de mineração, energia elétrica, papel e celulose ou do setor petrolífero realizam pesados investimentos em meio ambiente, enquanto que outros setores, como o setor financeiro, se concentram em atividades relacionadas com a promoção da cultura.

Os relatórios em RSC são um instrumento informativo mais para a sociedade em seu conjunto e, em particular, para os principais usuários da informação econômico-financeira. Os relatórios desta natureza possuem a capacidade de refletir o lado social e humano das empresas, a sua capacidade para respeitar o meio ambiente, os seus projetos sociais, a sua colaboração com todos os agentes da cadeia de fornecimento e o seu respeito aos clientes. A crescente importância do investimento social e no meio ambiente por parte das empresas faz com que estes tipos de relatórios comecem a se transformar num instrumento-chave adicional para a tomada de decisões por parte dos stakeholders.

\subsection{Análise da evolução do investimento em RSC}

Uma vez analisados os projetos, foi realizada uma análise temporal do investimento em RSC, agrupando-o em três indicadores: (1) indicador social interno (ISI); (2) indicador social externo (ISE) e (3) indicador do meio ambiente (IMA).

Indicador Social Interno (ISI): engloba o investimento nos projetos identificados sob a categoria de desenvolvimento profissional (2), fornecedores (9), consumidores e clientes (10) e empregados (11).

Indicador Social Externo (ISE): reflete o nível de investimento em projetos destinados à comunidade ou à sociedade em geral, relacionados com a educação, a cultura, a saúde, o esporte e o lazer, a luta contra a fome ou a segurança alimentar. Mais concretamente, os projetos relacionados com as categorias, 3, 4, 5, 6, 7 e 8 .

Indicador de Meio Ambiente (IMA): demonstra o investimento nos projetos identificados sob a categoria "meio ambiente" (1).

De acordo como pode ser observado no Gráfico 1, o investimento relacionado com os projetos sociais internos aumentou 81,03\%, passando de 18,9 milhões de reais em 2003 para 34,2 milhões em 2007. No entanto, o investimento social externo teve um aumento ainda maior durante o período 
analisado, alcançando um crescimento de 120,8\%. O investimento total no ano de 2003 alcançou 78,5 milhões de reais e aumentou gradativamente até 173,5 milhões de reais no ano de 2007. Os investimentos em meio ambiente tiveram um incremento de 41,7\% no período entre 2003 e 2007.

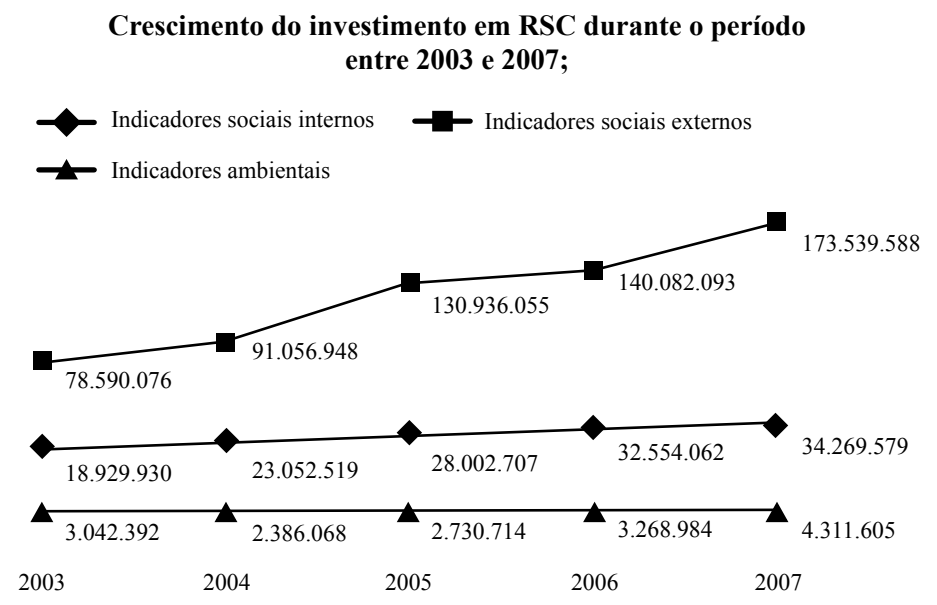

Gráfico 1: Crescimento do investimento em Responsabilidade Social Corporativa durante o período entre 2003 e 2007 (dados em Milhões de Reais).

Se eliminarmos a Petrobrás da amostra (Gráfico 2), os resultados são afetados, embora a tendência geral das três áreas de investimento no tempo não se vê alterada. $\mathrm{Na}$ área de investimento em projetos de meio ambiente se observa uma tendência de crescimento mais clara. Concretamente, os dados refletem um crescimento do investimento em meio ambiente de $211,09 \%$. No que se refere aos projetos de investimento externo e interno, também acontecem leves variações. Dessa maneira, como pode ser observado no gráfico 2 , o investimento relacionado com os projetos internos aumento $75,2 \%$, passando de 14,8 milhões de reais no ano de 2003 para 25,9 milhões em 2007. O investimento social externo teve um aumento maior durante o período comparado com os dados do gráfico 1, alcançando um crescimento de $176 \%$, passando de 36 milhões de reais no ano de 2003 para 99,5 milhões de reais no ano de 2007.

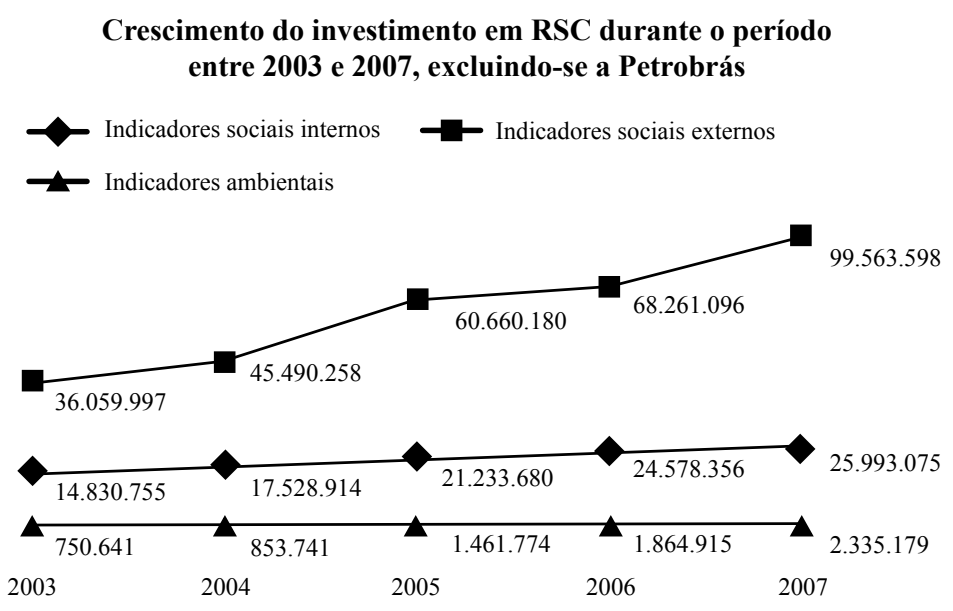

Gráfico 2: Crescimento do investimento em Responsabilidade Social Corporativa durante o período entre 2003 e 2007, excluindo-se a empresa Petrobrás (dados em Milhões de Reais).

A tabela 7 apresenta para cada setor industrial analisado a taxa de crescimento anual de cada uma das três grandes áreas de investimento. De forma consistente com os dados coletados no Gráfico 
1, a taxa média de crescimento mais alta corresponde ao investimento social externo, com $22,63 \%$, seguido do investimento social interno $(16,19 \%)$ e pelo investimento em meio ambiente, com 11,12\%.

A tabela 7 nos permite analisar a evolução do investimento em RSC em cada um dos setores industriais analisados. Os resultados são consistentes com os projetos identificados na Tabela 6 e constatam o interesse das empresas em desenvolver projetos intimamente relacionados com a atividade principal que elas desenvolvem. Podemos pegar como exemplo o setor de transporte aéreo e ferroviário, cujas atividades afetam de forma direta o meio ambiente através da emissão de $\mathrm{CO} 2$ na atmosfera. Este setor, juntamente com as empresas de produtos de higiene pessoal, é o que mais aumentou o seu investimento em meio ambiente ao longo do período analisado, embora também possa ser destacado o aumento do investimento em outros setores, como o de exploração mineral, o siderúrgico ou holding ${ }^{14}$. Diferentemente destes setores, o investimento em meio ambiente diminuiu no setor petroquímico y no de exploração de rodovias.

Tabela 7: Crescimento médio do investimento em responsabilidade social corporativa durante o período entre 2003 e 2007.

\section{Painel A: Indicadores de meio ambiente}

\begin{tabular}{l|c|c|c|c|c}
\hline \multirow{2}{*}{ Setores } & \multicolumn{3}{|c|}{ Crescimento anual (\%) do indicador ambiental } & Média \\
\cline { 2 - 6 } & $\mathbf{2 0 0 3 - 2 0 0 4}$ & $\mathbf{2 0 0 4 - 2 0 0 5}$ & $\mathbf{2 0 0 5 - 2 0 0 6}$ & $\mathbf{2 0 0 6 - 2 0 0 7}$ & I.MA \\
\hline Água e saneamento & 15,37 & 43,08 & 22,00 & $(1,99)$ & 19,62 \\
\hline Transporte aéreo e ferroviário & 177,78 & 98,88 & 386,74 & $(61,87)$ & 150,38 \\
\hline Exploração Mineral & 5,73 & 18,67 & 140,61 & 60,55 & 56,39 \\
\hline Petróleo, gás e biodiesel & $(33,12)$ & $(17,21)$ & 10,65 & 40,76 & 0,27 \\
\hline Siderurgia e metalurgia & 3,59 & 277,43 & $(1,02)$ & 35,81 & 78,95 \\
\hline Petroquímicos & - & - & $(66,11)$ & 1,31 & $(32,40)$ \\
\hline Papel e Celulose & $(62,26)$ & 102,93 & $(6,39)$ & $(33,31)$ & 0,24 \\
\hline Material de Transporte & 24,54 & 39,29 & 59,46 & $(12,77)$ & 27,63 \\
\hline Energia Elétrica & 143,66 & $(16,00)$ & 41,43 & 5,77 & 43,71 \\
\hline Financeiro & $(59,82)$ & 83,13 & 14,19 & 14,39 & 12,97 \\
\hline Seguradora & - & - & 67,07 & $(48,03)$ & 9,52 \\
\hline Máquinas e equipamentos industriais & $(6,26)$ & 60,59 & $(33,99)$ & 94,43 & 28,69 \\
\hline Alimentação & 1,83 & 54,53 & 39,02 & 11,41 & 26,70 \\
\hline Holding Diversificado & 30,93 & 36,25 & 23,27 & 240,62 & 82,77 \\
\hline Embalagem & - & - & - & - & - \\
\hline Exploração de rodovias & - & $(2,59)$ & $(20,34)$ & $(27,24)$ & $(16,72)$ \\
\hline Serviços Diversos & - & - & - & - & - \\
\hline Cigarros e fumo & 109,02 & $(68,53)$ & 0,28 & 71,82 & 28,15 \\
\hline Aluguel de carros & - & - & - & - & - \\
\hline Produtos de higiene pessoal & 148,31 & 89,76 & $(60,16)$ & 317,38 & 123,82 \\
\hline Média & $\mathbf{( 2 1 , 5 7 )}$ & $\mathbf{1 4 , 4 4}$ & $\mathbf{1 9 , 7 1}$ & $\mathbf{3 1 , 8 9}$ & $\mathbf{1 1 , 1 2}$ \\
\hline
\end{tabular}

\footnotetext{
$\overline{14}$ O aumento do investimento em meio ambiente do setor "Holdings Diversificadas" (representado pela empresa Ultrapar) está relacionado com uma melhoria nos processos de aproveitamento de recursos naturais a partir do ano de 2006. A empresa utilizou programas e projetos de preservação ambiental para reduzir e controlar a emissão de agentes poluidores e o lixo industrial. Além disso, otimizou o uso de matérias-primas limpas e adotou a reciclagem, além de conscientizar os seus stakeholders sobre a importância do meio ambiente.
} 


\section{Painel B: Indicadores sociais externos}

\begin{tabular}{l|c|c|c|c|c}
\hline \multirow{2}{*}{ Setores } & \multicolumn{3}{c|}{ Crescimento anual (\%) do indicador externo } & Média \\
\cline { 2 - 6 } & $\mathbf{2 0 0 3 - 2 0 0 4}$ & $\mathbf{2 0 0 4 - 2 0 0 5}$ & $\mathbf{2 0 0 5 - 2 0 0 6}$ & $\mathbf{2 0 0 6 - 2 0 0 7}$ & I.EXT. \\
\hline Água e saneamento & 2,82 & 35,93 & 16,65 & 12,61 & 17,00 \\
\hline Transporte aéreo e ferroviário & 49,81 & 11,72 & 50,71 & $(12,62)$ & 24,91 \\
\hline Exploração Mineral & 1,61 & 96,24 & 46,08 & 4,29 & 37,05 \\
\hline Petróleo, gás e biodiesel & 7,14 & 54,23 & 2,20 & 3,00 & 16,64 \\
\hline Siderurgia e metalurgia & 138,16 & 13,22 & $(10,14)$ & 299,98 & 110,31 \\
\hline Petroquímicos & - & - & 3,78 & $(11,84)$ & $(4,03)$ \\
\hline Papel e Celulose & $(30,28)$ & 19,93 & $(18,09)$ & 40,19 & 2,94 \\
\hline Material de Transporte & $(3,23)$ & $(3,44)$ & 35,61 & $(40,66)$ & $(2,93)$ \\
\hline Energia Elétrica & 24,43 & 21,89 & 27,88 & 2,65 & 19,21 \\
\hline Financeiro & 11,37 & 49,81 & 4,85 & 26,05 & 23,02 \\
\hline Seguradora & - & - & 23,81 & 14,57 & 19,19 \\
\hline Máquinas e equipamentos industriais & 19,89 & 22,93 & 9,97 & 74,02 & 31,70 \\
\hline Alimentação & 46,25 & 174,93 & $(4,04)$ & 29,92 & 61,77 \\
\hline Holding Diversificado & 37,32 & 4,13 & $(61,91)$ & 269,51 & 62,26 \\
\hline Embalagem & - & - & - & - & - \\
\hline Exploração de rodovias & - & - & - & 29,18 & 29,18 \\
\hline Serviços Diversos & - & - & $(12,04)$ & $(100,00)$ & $(56,02)$ \\
\hline Cigarros e fumo & 12,30 & 4,79 & 2,34 & 16,87 & 9,07 \\
\hline Aluguel de carros & - & - & - & 38,57 & 38,57 \\
\hline Produtos de higiene pessoal & - & - & - & 6,32 & 6,32 \\
\hline Média & $\mathbf{1 5 , 8 6}$ & $\mathbf{4 3 , 8 0}$ & $\mathbf{6 , 9 9}$ & $\mathbf{2 3 , 8 8}$ & $\mathbf{2 2 , 6 3}$ \\
\hline
\end{tabular}

\section{Painel C: Indicadores sociais internos}

\begin{tabular}{l|c|c|c|c|c}
\hline \multirow{2}{*}{\multicolumn{1}{c|}{ Setores }} & \multicolumn{3}{c|}{ Crescimento anual (\%) do indicador interno } & Média \\
\cline { 2 - 6 } & $\mathbf{2 0 0 3 - 2 0 0 4}$ & $\mathbf{2 0 0 4 - 2 0 0 5}$ & $\mathbf{2 0 0 5 - 2 0 0 6}$ & $\mathbf{2 0 0 6 - 2 0 0 7}$ & I.INT \\
\hline Água e saneamento & 10,50 & 0,52 & 16,24 & $(0,65)$ & 6,65 \\
\hline Transporte aéreo e ferroviário & 46,17 & 21,42 & 30,70 & 45,89 & 36,05 \\
\hline Exploração Mineral & 28,87 & 14,04 & $(14,65)$ & 126,03 & 38,57 \\
\hline Petróleo, gás e biodiesel & 34,75 & 22,55 & 17,83 & 3,77 & 19,72 \\
\hline Siderurgia e metalurgia & 27,82 & 38,93 & 34,89 & $(46,36)$ & 13,83 \\
\hline Petroquímicos & - & - & 20,65 & 20,98 & 20,81 \\
\hline Papel e Celulose & 23,96 & 16,73 & $(0,11)$ & $(2,76)$ & 9,46 \\
\hline Material de Transporte & 40,14 & 5,86 & 8,32 & 28,63 & 20,74 \\
\hline Energia Elétrica & 10,63 & 13,27 & 14,36 & $(16,50)$ & 5,44 \\
\hline Financeiro & 14,25 & 18,05 & 16,01 & 8,35 & 14,17 \\
\hline Seguradora & -1 & - & 25,66 & $(3,74)$ & 10,96 \\
\hline Máquinas e equipamentos industriais & 30,78 & 6,27 & 23,74 & 18,24 & 19,76 \\
\hline Alimentação & 34,28 & 25,93 & 12,03 & 18,23 & 22,62 \\
\hline Holding Diversificado & 19,25 & $(4,73)$ & 17,72 & 29,62 & 15,47 \\
\hline
\end{tabular}

\footnotetext{
${ }_{15}$ Conforme dados do Instituto Brasileiro de Siderurgia (IBS, 2007), no periodo compreendido entre os anos de 1994 e 2006, o setor siderúrgico fez investimentos na ordem de US\$18,9 bilhões.
} 


\begin{tabular}{l|c|c|c|c|c}
\hline Embalagem & 42,12 & 4,32 & 10,01 & $(100,00)$ & $(10,89)$ \\
\hline Exploração de rodovias & - & 53,54 & $(20,18)$ & 51,18 & 28,18 \\
\hline Serviços Diversos & - & - & 4,51 & $(100,00)$ & $(47,75)$ \\
\hline Cigarros e fumo & 11,11 & 19,23 & 18,85 & 7,76 & 14,24 \\
\hline Aluguel de carros & - & - & 53,18 & 14,13 & 33,65 \\
\hline Produtos de higiene pessoal & 101,15 & 60,94 & 2,77 & 60,35 & 56,30 \\
\hline Média & $\mathbf{2 1 , 7 8}$ & $\mathbf{2 1 , 4 7}$ & $\mathbf{1 6 , 2 5}$ & $\mathbf{5 , 2 7}$ & $\mathbf{1 6 , 1 9}$ \\
\hline
\end{tabular}

Em relação ao investimento externo em RSC, ele cresceu de forma significativa no setor de "siderurgia e metalurgia". Este crescimento foi o resultado de um cenário de expansão e competitividade favorável para o setor em nível mundial ${ }^{15}$, bem como do pesado investimento realizado em projetos educativos para a comunidade. As empresas deste setor também desenvolveram projetos na área de esportes e saúde. Juntamente com este setor também se destaca o crescimento do investimento realizado pelo setor de alimentação, que está focado fundamentalmente na área de esportes. Os projetos relacionados com o esporte são uma boa forma de divulgação da marca e da atividade da empresa, e este foi o principal objetivo das empresas do setor de alimentação, que nos últimos dois anos investiram no patrocínio de equipes esportivas em competições nacionais e internacionais. $\mathrm{O}$ setor de "holding" também se destaca pelo crescimento do investimento social externo, com a criação do projeto educativo Ultra Formare, que tem como objetivo a formação profissional de adolescentes das classes sociais mais baixas, bem como apoiar financeiramente as instituições educacionais.

Finalmente, na área de investimento social interno em RSC as taxas de crescimento do investimento dos setores são moderadas, com reduções somente em setores de baixo investimento em RSC. Como pode ser observado no Painel $\mathrm{C}$ da Tabela 7, o setor de serviços diversos diminuiu o seu investimento no período de 2006 a 2007 em 100\%, seguido do setor de embalagem, com uma redução similar no mesmo período. Esta diminuição se deve ao fato de as empresas, principalmente as do setor de serviços diversos, terem eliminado os seus investimentos prévios em projetos de capacitação profissional dos seus empregados. O setor de produtos de uso pessoal (empresa Natura) teve o maior crescimento médio de investimento interno no período $(56,3 \%)$, que se justifica pelos investimentos em programas de educação e de qualidade de vida dos seus empregados, bem como pelo desenvolvimento de programas de treinamento da equipe de vendas da empresa.

É importante que as empresas desenvolvam projetos cujo principal objetivo esteja sempre relacionado com a sua atividade principal. Ou seja, elas devem evitar investir em projetos que não tenham vínculo com a atividade da empresa, com a sua estratégia de desenvolvimento e crescimento ou com a sua imagem de marca perante os consumidores. As boas práticas também devem vir acompanhadas de uma boa gestão da RSC. Um exemplo claro é o caso das empresas do setor de transporte aéreo e ferroviário, no qual 31 projetos estão destinados ao acompanhamento da saúde dos seus empregados, como pilotos de aviões, motoristas de caminhões e maquinistas. As consequências derivadas do estresse que estes profissionais podem chegar a sofrer fazem com que seja imprescindível proteger a sua saúde com o intuito de se evitarem baixas trabalhistas que venham a afetar tanto a própria empresa quanto o conjunto da sociedade. Outro exemplo é o do setor de exploração de rodovias, com 12 projetos específicos de formação dos empregados em funções operacionais, tais como manipulação de produtos perigosos; prevenção de acidentes de trabalho; atendimento ao usuário nas rodovias; treinamento operacional em assuntos de arrecadação monetária; atendimento pré-hospitalar em caso de acidentes em rodovias, entre outros.

\section{CONCLUSÕES}

Nos últimos anos, a responsabilidade social corporativa (RSC) evoluiu muito rapidamente no universo empresarial brasileiro. No princípio, a filantropia deu lugar a projetos de voluntariado e ao 
investimento social nas comunidades do ambiente empresarial. Mais tarde, começaram a ser protagonistas a ética e a transparência com os agentes interessados na atividade empresarial. Finalmente, o objetivo era mostrar que a RSC significa, na prática, sinônimo de boa gestão. Na atualidade, a maior preocupação das empresas surge em relação à sustentabilidade. Para concluir, as questões ambientais e sociais, que muitas vezes foram ignoradas pelas organizações, fazem parte das suas estratégias na atualidade. Em todos os setores empresariais analisados o debate está enfocado em como transformar a sustentabilidade numa oportunidade.

Como já foi mencionado anteriormente, o objetivo deste trabalho é analisar os avanços em responsabilidade social no Brasil, colocando ênfase no tipo de informação apresentada e no nível dos investimentos realizados no período entre os anos de 2003 e 2007. A análise empírica está baseada no conteúdo dos relatórios de RSC publicados por um total de 48 empresas que possuem cotação na Bovespa, que apostam e informam sobre as suas atividades a favor da RSC.

Os resultados da análise empírica deixam evidente que no contexto empresarial atual no qual a RSC alcança um crescente interesse, a forma como as organizações empresariais desenvolvem os seus produtos e se relacionam com a sociedade está mudando. Concretamente, na área de meio ambiente as empresas da amostra priorizam os "produtos responsáveis" e as tecnologias de produção "limpas" e com um impacto ambiental reduzido. A grande maioria adota também o discurso do "marketing responsável" e do "consumo consciente", desenvolvendo projetos relacionados com o impacto da sua atividade principal na sociedade.

De acordo com o conteúdo dos relatórios anuais analisados, as prioridades e os desafios estratégicos se relacionam com o desenvolvimento dos recursos humanos através do desenvolvimento profissional; do aumento da qualidade dos processos, produtos e serviços; do investimento em inovação, em pesquisa e desenvolvimento; do crescimento e expansão geográfica da firma e da redução de custos. Para o desenvolvimento destas estratégias, as empresas estão conscientes da necessidade de se investir na qualidade do atendimento ao cliente, na educação, nas relações com fornecedores e terceiros, na saúde e segurança dos empregados, bem como na análise do risco sócio-ambiental das atividades da empresa.

Finalmente, a análise empírica também deixa evidente a falta de uniformidade na apresentação dos relatórios de RSC apresentados pelas empresas devido à ausência de uma estrutura ou de um formato normalizado para a sua publicação. Neste sentido, fica evidente a necessidade de potencializar um formato único de apresentação deste tipo de relatório. Os resultados desta pesquisa vêm confirmar a necessidade de se estabelecerem alguns padrões mínimos de apresentação baseados nos indicadores GRI (Global Reporting Initiative), que constituem, no momento atual, o formato de apresentação mais completo deste tipo de relatório, adaptável a empresas de tamanhos, países e setores industriais diferentes.

\section{REFERÊNCIAS}

ADAMS, C. A.; HILL, W. ; ROBERTS, C. B. 1998. Corporate social reporting practices in Western Europe; legitimating corporate behaviour? The British Accounting Review, 30 (1):1-21.

ANDRADE, J. C. S.; MARINHO, M. M. O.; CARDOSO, L. F. ; SALATIEL, M. 2002. Relatório sócio-ambiental corporativo e produção sustentável. In: ANAIS DO XXXVII CONGRESSO LATINOAMERICANO DE ESCOLAS DE ADMINISTRAÇÃO (CLADEA), Porto Alegre, 2002, 22-25 p.

ARAÚJO, F. J. 2003. Auditando o balanço social. Revista Brasileira de Contabilidade, XXXII (140): 83-89.

BALANÇO SOCIAL. Disponível em: http://www.balancosocial.org.br. Acesso em: 12/10/2006. 
BATISTA, H. M. 2000. Balanço social: uma mudança de estratégia a favor da política social. In: XVI CONGRESSO BRASILEIRO DE CONTABILIDADE. Goiânia.

CARNEIRO, G. A. S. 1994. Balanço Social: Histórico, Evolução e Análise de Algumas Experiências Selecionadas. São Paulo: Fundação Getúlio Vargas.

CARROL, A. B. e BUCHHOLTZ, A. K. 2000. Business \& Society: Ethics and Stakeholder Management, $4^{\mathrm{a}}$ ed. South-Western College Publishing, Cincinnati.

COMISSÃO DE VALORES MOBILIÁRIOS. Dados e Publicações CVM. Balanço Social: A posição da CVM. Disponível em: http://www.cvm.gov.br. Acesso em: 25/11/2006.

COMISION DE LAS COMUNIDADES EUROPEAS. Libro verde: promover un cuadro europeo para la responsabilidad social de las empresas. Bruselas, 18.7.2001. COM (2001) 366 final.

COMISION DE LAS COMUNIDADES EUROPEAS. Comunicación de la Comisión relativa a la responsabilidad social de las empresas: una contribución empresarial al desarrollo sostenible. Bruselas, 2/7/2002. COM (2002) 347 final.

COMISIÓN EUROPEA. Diez años de la Estrategia Europea de Empleo. Luxemburgo: Oficina de Publicaciones Oficiales de las Comunidades Europeas. 2007 - 43 pp. - 17.6 x 25 cm. ISBN 978-92-79-06583-5.

CONSELHO FEDERAL DE CONTABILIDADE. Resolução CFC no 1.003/04 (NBC T 15 - Informações de Natureza Social e Ambiental). Disponível em: http://www.cfc.org.br. Acesso em: 25/11/2006.

DIERKES, M.; ANTAL, A. B. 1985. The usefulness and use of social reporting information. Accounting, Organizations and Society, 10 (1):29-34.

ETHOS. Instituto Ethos de Empresas e Responsabilidade Social. Guia de Elaboração do Balanço Social - 2002. Disponível em: www.ethos.org.br. Acesso em: 28/11/2006.

FREIRE, F. S.; REBOUÇAS, T. R. S. 2001. Uma Descrição Sucinta do Balanço Social Francês, Português, Belga e Brasileiro. In: SILVA, C. A. T. e FREIRE, F. S. (Orgs.), Balanço Social: Teoria e Prática. São Paulo, Atlas, 176 p.

GONELLA, C. 1998. Making values count: contemporary experience in social and ethical accounting, auditing, and reporting. London, The Association of Chartered Certified Accountants.

GRI - Global Reporting Initiative. 2002. Sustainability Reporting Guidelines. Amsterdam.

GRI - Global Reporting Initiative. 2006. Sustainability Reporting Guidelines. Amsterdam.

GRI - Global Reporting Initiative. 2006. Sustainability Reporting Guidelines on Economic, Environmental and Social Performance. Disponível em: http://www.globalreporting.org. Acesso em: 29/10/2007.

IBASE - Instituto Brasileiro de Análises Sociais e Econômicas. Transformando a frieza dos números em responsabilidade social. Disponível em: http://www.ibase.br. Acesso em: 12/10/2006. 
INSTITUTE OF SOCIAL AND ETHICAL ACCOUNTABILITY. Disponível em: http://www.accountability.org.uk. Acesso em: 15/10/2006.

KROETZ, C. E. S. 2000. Balanço social: teoria e prática. São Paulo, Atlas, 162 p.

LEWIS, L.; UNERMAN, J. 1999. Ethical Relativism: A Reason for Differences in Corporate Social Reporting? Critical Perspectives on Accounting, 10 (4):521-547.

LINE, M; HAWLEY, H. ; KRUT, R. 2002. The development of Global Environmental and Social Reporting. Corporate Environmental Strategies, 9 (1):69-78.

MOREIRA, J. 2001. Balanço Social e Demonstração do Valor Adicionado como instrumentos gerenciais. In: ANAIS DO SEMINÁRIO USP DE CONTABILIDADE I. São Paulo.

NEGRA, C. A. S; TEIXEIRA, F. S; CARMO, R. F. 2002. O balanço social na gestão das instituições de ensino superior. Revista Brasileira de Contabilidade, 138 (6), 69- 87.

PRESTON, L. E. 1981. Research on corporate social reporting: Directions for development. Accounting, Organizations and Society, 6 (3):255-262.

REIS, C. N.; MEDEIROS, L. E. 2007. Responsabilidade social das empresas e balanço social: Meios propulsores de desenvolvimento econômico e social. São Paulo, Atlas, 188 p.

ROBERTS, R. W. 1998. A stakeholder approach to the Corporate Single Audit. Critical Perspectives on Accounting, 9 (2):227-232.

SHAOUL, J. 1998. Critical financial analysis and accounting for stakeholders. Critical Perspectives on Accounting, 9 (2):235-249.

SIQUEIRA, J. R. M.; VIDAL, M. C. R. 2002. Mensuração do impacto social das empresas: Uma abordagem qualitativa aos balanços sociais brasileiros. In: ANAIS DO XXXVII CONGRESSO LATINO-AMERICANO DE ESCOLAS DE ADMINISTRAÇÃO (CLADEA), Porto Alegre.

SIQUEIRA, J. R. M.. 2003. Balanços Sociais Brasileiros: Uma Análise de seu Estágio Atual. In: ANAIS DO $3^{\circ}$ CONGRESSO USP DE CONTROLADORIA E CONTABILIDADE, São Paulo.

SUTTON, S. G.; ARNOLD, V. 1998. Towards a framework for Corporate Single Audit: Meeting financial statement users' needs. Critical Perspectives on Accounting, 9 (2):177-191.

TEOH, H.; THONG, G. 1984. Another look at corporate social responsibility and reporting: An empirical study in a developing country. Accounting, Organizations and Society, 9 (2):189-206.

TINOCO, J. E. P. 2001. Balanço social: uma abordagem da transparência e da responsabilidade pública das organizações. São Paulo, Atlas, 248 p. 